\title{
Job Satisfaction, Effort, and Performance: A Reasoned Action Perspective
}

\author{
Icek Ajzen ${ }^{1}$
}

ABSTRACT

\begin{abstract}
In this article the author takes issue with the recurrent reliance on job satisfaction to explain jobrelated effort and performance. The disappointing findings in this tradition are explained by lack of compatibility between job satisfaction--a very broad attitude--and the more specific effort and performance criteria. Moreover, attempts to apply the expectancy-value model of attitude to explore the determinants of effort and performance suffer from reliance on unrepresentative sets of beliefs about the likely consequences of these behaviors. The theory of planned behavior (Ajzen, 1991, 2012), with its emphasis on the proximal antecedents of job effort and performance, is offered as an alternative. According to the theory, intentions to exert effort and to attain a certain performance level are determined by attitudes, subjective norms, and perceptions of control in relation to these behaviors; and these variables, in turn, are a function of readily accessible beliefs about the likely outcomes of effort and performance, about the normative expectations of important others, and about factors that facilitate or hinder effective performance.
\end{abstract}

KEY WORDS: $\quad$ job satisfaction, job performance, expectancy-value model, theory of planned behavior.

JEL Classification: A120

${ }^{1}$ University of Massachusetts, USA

\section{Introduction}

The productivity of its workforce is of vital importance to any commercial enterprise and it is therefore hardly surprising that job performance has been the focus of much research in organizational behavior. By far the most popular approach invokes the concept of job satisfaction to explain performance under the assumption that a high level of satisfaction leads to increased productivity on the job whereas dissatisfaction undermines productivity. Indeed, the proposed relation between job satisfaction and performance has been called the "Holy Grail" of organizational behavior (Landy, 1989). Various measures have been developed

-

Corespondence concerning to this article should be addressed to: aizen@psych.umass.edu over the years to assess job satisfaction (e.g., Smith, 1974) as well as job performance (see Viswesvaran \& Ones, 2000), and a great number of studies have investigated the relation between these variables. The results of these efforts have been surprisingly disappointing; most studies have reported very low and often nonsignificant correlations. Indeed, a meta-analysis of 312 data sets by Judge, Thoresen, Bono, and Patton (2001) revealed a mean correlation of only 18 between job satisfaction and performance (see also Iaffaldano \& Muchinsky, 1985).

Going beyond overall job satisfaction, investigators have also assessed satisfaction with various specific aspects of the work environment: satisfaction with the work itself, with pay, coworkers, supervision, and opportunities for promotion (see Kinicki, McKee-Ryan, Schriesheim, \& Carson, 2002; Smith, Kendall, \& Hulin, 

Product-moment correlation coefficients relating the two kinds of responses are rarely above .30, and often are near zero" (p. 65). Based on a much larger set of studies, a recent meta-analysis of research on the attitude-behavior relation (Greenwald, Poehlman, Uhlmann, \& Banaji, 2009) revealed the same general pattern. In their synthesis, the investigators compared the predictive validity of traditional, explicit attitude measures and more recently developed implicit measures designed to circumvent self-presentation biases. The mean weighted correlation between explicit attitude measures and behavior across 156 data sets was .36, and the mean correlation between implicit attitude measures and behavior across 184 data sets was .27 . When examining only studies on the relation between prejudicial attitudes and discriminatory behavior where self-presentation biases may be particularly strong, the mean weighted attitude-behavior correlations were .12 (28 data sets) for explicit attitude measures and .24 (32 data sets) for implicit measures. Clearly, for anyone inclined to rely on attitudes to predict and explain human behavior, these low correlations are extremely discouraging. And, as we saw earlier, this pattern in repeated in research on the relation between attitudes toward one's job, i.e., job satisfaction, and productivity.

\section{The Principle of Compatibility}

To understand why attitudes are often found to be poor predictors of behavior we must draw a distinction between two kinds of attitudes: general attitudes toward physical objects, institutions, groups, policies, or one's job-attitudes of the kind studied in most early research on the attitude-behavior relation; and attitudes toward performing particular behaviors (exercising, using contraception, getting a cancer screening, hiring a member of a minority group, participating in an election, using public transit, recycling, working long hours, and so forth). Ajzen and Fishbein (1977) formulated the principle of compatibility to help clarify the nature of the relation between verbal attitudes and overt actions. According to this principle, attitudes and behavior correlate with each other to the extent that they refer to the same action, target, context, and time elements. Measures of behavior typically involve a specific action (e.g., making friends) and target (e.g., a gay person), and often also a specific context (e.g., at work) and time frame (e.g., in the next 6 months). By way of contrast, general attitudes (e.g., toward gays) identify only the target; they do not specify any particular action, context, or time element. This lack of compatibility, especially in the action element, is said to be at the root of the low and often nonsignificant correlations between general attitudes and specific behaviors directed at the target of the attitude.

This is not to say, however, that general attitudes are irrelevant when it comes to the prediction of behavior. According to the principle of compatibility, general attitudes predict broad patterns or aggregates of behavior. When we aggregate different behaviors directed at the same target, we generalize across actions, contexts, and time elements, thus assuring compatibility with equally broad attitudes toward the target in question. Consistent with this line of reasoning, attitudes toward religion and the church, though largely unrelated to individual behaviors in this domain, were shown to correlate strongly with broad patterns of religious behavior (Fishbein and Ajzen 1974); and attitudes toward protection of the environment predicted an aggregate of individual behaviors protective of the environment (Weigel and Newman 1976). However, when we are interested in predicting and understanding the determinants of specific actions rather than general behavioral patterns, the principle of compatibility suggests that we must assess the attitude that corresponds to the behavior of interest in terms of its action, target, context, and time elements. In other words, instead of measuring people's attitudes toward a general object, such as their jobs, we have to assess their attitudes toward the particular behavior we are trying to predict. Empirical support for the compatibility principle can be found in several reviews of the literature (Ajzen and Fishbein 1977; Kraus 1995; see also Fishbein and Ajzen 2010).

The principle of compatibility has important implications that, to the best of my knowledge, have not been explored in relation to job satisfaction. It suggests that satisfaction or dissatisfaction with one's job, being a broad attitude, should be predictive of a general pattern of work-related activities but not of any single behavior. Thus, we would expect job satisfaction to correlate well with an aggregate across a whole range of different behaviors including, but not limited to, job performance. In addition to job performance, the aggregate might include such behaviors as tardi- 

\& Suttle, 1973; Vroom, 1964). The best known of these approaches is Vroom's (1964) expectancy-instrumentality-value theory of work motivation. When applied to job performance, the theory can be described as follows. Effort exerted on the job (the behavior) is determined by the worker's belief or expectation (E) that increased effort will lead to a certain level of performance (the outcome) multiplied by the subjective value or evaluation of this performance level. The subjective value of this (first-level) outcome, in turn, is a function of the perceived instrumentality (I) of the outcome for the attainment of various (second-level) outcomes (e.g., pay, promotion, recognition), weighted by their subjective values (V). This model can be illustrated as follows.

Figure 1. Expectancy-value model of job performance

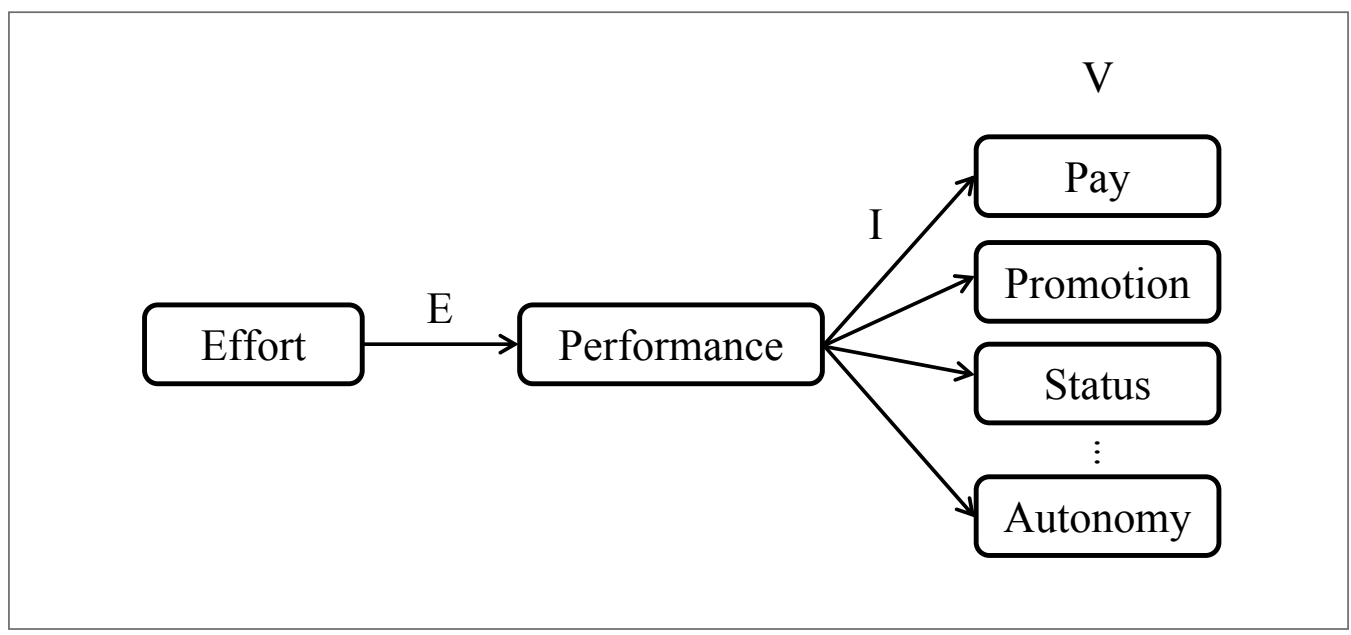

Source: own study based on Vroom, V. H. (1964). Work and motivation. New York: Wiley.

Although intuitively appealing, empirical tests of Vroom's model have been largely disappointing. For example, Avery and Neel (1974) applied the model to predict the work-related motivation of engineers in a large utility company. Supervisors rated each of the engineers on seven elements reflective of motivation and effort: professional identification, job curiosity, team attitude, task concentration, independent selfstarter, persistence, and organizational identification. In addition, an overall effort score was obtained by aggregating the seven specific ratings. As a measure of expectancy (E), the participants indicated, on a 5-point scale, their agreement with the statement, "If I apply a great deal of effort in my job, that is, work very hard, I will be regarded by my supervisor as an effective performer." To assess instrumentality (I), the investigators asked participants to rate, again on a 5-point scale, the likelihood that effective performance would lead to each of 10 possible outcomes: making use of abilities, accomplishments, advancement, supervise others, fair company policies and practices, high salary, getting along with coworkers, praise, use own judgment, and steady and secure employment. Finally, the participants were asked to distribute 100 points among these 10 outcomes according to their perceived importance. These ratings represented the valence $(V)$ or subjective value of each outcome.

Consistent with Vroom's model, the investigators multiplied an individual's (i) instrumentality rating of each outcome $j$ by the outcome's valence, summed the products across the 10 outcomes $\left(\sum \mathrm{I}_{\mathrm{ij}} \mathrm{V}_{\mathrm{ij}}\right)$, and then multiplied the resulting index by the expectancy measure $\left(E_{i} \sum I_{i j} V_{i j}\right)$. This final index of employee motivation was correlated with each of the six behavioral elements of effort, as rated by the supervisors, and with the summed effort score. Because age correlated significantly, albeit weakly, with the criterion scores, the sample was divided into a relatively older group (41 years 

to consider the perceived direct effects of increased effort (unmediated by performance) on work-related outcomes. Unfortunately, the results are not much improved by taking this approach. In their meta-analysis, Van Eerde and Thierry (1996) reported a mean correlation of .32 between this new expectancy-value index and effort (based on 19 data sets) and a mean correlation of 27 between the new index and job performance (based on 18 data sets).

Although linking effort directly to its likely outcomes is preferable to Vroom's mediational model and is consistent with the expectancy-value model of attitude, the problem with the approach taken by investigators in this area is that they tend to select an a priori set of outcomes and assume that these outcomes are the actual determinants of attitudes toward effort. A moment's reflection reveals the fallacy of this assumption. It stands to reason that attitudes toward exerting effort on the job are influenced by many perceived consequences other than such workrelated outcomes as higher pay, promotion, praise, and so forth. Indeed, employees might believe that increased effort would result in a variety of possible negative outcomes such as less time for leisure activities, less energy to devote to one's spouse and children, and deterioration of physical health. Therefore, even if increased effort were perceived to have certain positive work-related outcomes, such as higher pay or promotion, the perceived negative outcomes could cancel or even out-weigh the positive outcomes. In short, instead of simply assuming that work-related outcomes are important to people's attitudes toward effort, we must conduct formative research to ascertain the kinds of beliefs people actually hold about increasing their effort on the job. According to theory, it is these accessible beliefs that determine their attitudes toward effort and that will influence job performance (see Mitchell \& Biglan, 1971).

Some empirical support for this argument can be found in a study by Matsui and Ikeda (1976). In one condition of the experiment, the investigators asked high-school students to generate five outcomes they believed would result from studying hard. In a second condition they used a standard list of 10 outcomes generated by the investigators. The number of hours spent daily on homework was used as an index of effort and grades at the latest examinations as a measure of performance. An expectancy-value index based on the self-generated outcomes correlated .44 with effort and .36 with performance, compared to correlations of .28 and .23, respectively, for the index based on the 10 standard outcomes. It should be noted, however, that it is possible to obtain a strong correlation between a belief composite and a direct attitude measure even when the belief statements are constructed by the investigator rather established empirically. This is likely to be the case when the beliefs constructed by the investigator refer to a representative set of potential outcomes. When, as is the practice in research on job performance, the belief statements deal only with positive outcomes, strong correlations cannot be expected. Also, and perhaps more important, the advantage of eliciting beliefs in the research population is that, in theory, readily accessible beliefs serve as the causal antecedents of attitude, i.e., they constitute formative indicators of attitude. A representative list of beliefs constructed by the investigator can serve as reflective indicators of the attitude, and can therefore correlate quite well with a direct attitude measure, but there is no assurance that these beliefs have a causal influence on the attitude.

\section{Going Beyond Attitudes}

Subjective norms. In the TPB, beliefs about the likely outcomes of a behavior are known as behavioral beliefs. However, intentions to perform a particular behavior are assumed to be influenced by two other kinds of considerations as well. In addition to the likely outcomes of a behavior, people also consider the wishes of important social referents. These perceived expectations are termed normative beliefs, and, according to the TPB, the normative beliefs regarding different social referents (e.g., spouse, close friends, coworkers, supervisor) combine to produce an overall perceived social pressure to perform the behavior of interest, or subjective norm. Drawing an analogy to the expectancy-value model of attitude toward a behavior, it is assumed that the prevailing subjective norm is determined by the total set of readily accessible normative beliefs concerning the expectations of important referents. Each normative belief is multiplied by the person's motivation to comply with the referent, and the resulting products are summed across all accessible referents. 

behavioral control in direct proportion to the person's subjective probability that the control factor is present. Perceived power and subjective probability are multiplied, and the resulting products are summed across all accessible control factors. In support of this model, empirical evidence shows strong correlations between direct measures of perceived behavioral control and the composite of control beliefs. For example, in an analysis of 16 of their own studies in the health domain, Gagné and Godin (2000) found a median correlation of .57 between control belief composites and direct measures of perceived behavioral control, and in a meta-analysis of 18 studies on a variety of different behaviors, Armitage and Conner (2001) reported a mean correlation of .52 .

\section{Summary and Conclusions}

For obvious practical and theoretical reasons, a great deal of research continues to be devoted to the identification of factors that determine work-related effort and performance. Consistent with the principle of compatibility, I advocate a shift from the focus on job satisfaction--a broad attitude with limited relevance for the relatively specific criteria of interest--to a consideration of the proximal antecedents of effort and performance. Relying on the theory of planned behavior, we can identify three factors that guide people's decisions or intentions to exert effort on the job: attitudes toward this behavior, perceived social pressure to exert or not to exert effort (subjective norms), and perceptions of behavioral control or self efficacy in relation to exerting effort. The same three variables can be assessed if the criterion is job performance. In this case, however, it must be realized that performance is not a behavior but rather a possible outcome of various behaviors related to effort. Attitudes, subjective norms, and perceptions of control with respect to performance would be expected to predict intentions to attain a certain performance level, but these intentions may be thwarted by environmental constraints, thus requiring that the investigator consider the employee's actual control over attainment of the intended outcome.

A fundamental feature of the TPB is its adoption of the expectancy-value model to describe the effects of beliefs on attitudes, subjective norms, and perceptions of behavioral control. In the context of trying to understand effort on the job, it is assumed that behav- ioral beliefs about the likely consequences of effort determine attitudes toward effort, that normative beliefs about the expectations of important others regarding effort lead to the formation of a subjective norm, and that control beliefs about the factors that facilitate or interfere with effort produce a sense of perceived behavioral control. Rather than relying on a priori assumptions about the nature of these beliefs, the TPB insists that formative research be conducted to identify the behavioral, normative, and control beliefs that are readily accessible in the research population. These readily accessible beliefs are said to constitute the psychological determinants of intentions to exert effort and thus to influence actual effort and performance on the job. The TPB does not specify where these beliefs come from; it merely points to a host of possible background factors that may influence the beliefs people hold: factors of a personal nature such as personality and broad life values; demographic variables such as education, age, gender, and income; and exposure to media and other sources of information. Factors of this kind are expected to influence intentions and behavior indirectly by their effects on the theory's more proximal determinants (Fishbein \& Ajzen, 2010).

\section{References}

1. Ajzen, I. (1985). From intentions to actions: A theory of planned behavior. In J. Kuhl \& J. Beckman (Eds.), Action-control: From cognition to behavior (pp. 11-39). Heidelberg, Germany: Springer.

2. Ajzen, I. (1991). The theory of planned behavior. Organizational Behavior and Human Decision Processes, 50(2), 179-211.

3. Ajzen, I. (2005). Attitudes, personality, and behavior (2nd ed.). Maidenhead, UK: Open University Press.

4. Ajzen, I. (2012). The theory of planned behavior. In P. A. M. v. Lange, A. W. Kruglanski \& E. T. Higgins (Eds.), Handbook of theories of social psychology (Vol. 1, pp. 438-459). London, UK: Sage Publications.

5. Ajzen, I., \& Fishbein, M. (1977). Attitude-behavior relations: A theoretical analysis and review of empirical research. Psychological Bulletin, 84(5), 888-918

6. Ajzen, I., \& Fishbein, M. (1980). Understanding attitudes and predicting social behavior. Englewood-Cliffs, NJ: Prentice-Hall. 
7. Ajzen, I., \& Fishbein, M. (2000). Attitudes and the attitude-behavior relation: Reasoned and automatic processes. In W. Stroebe \& M. Hewstone (Eds.), European review of social psychology (Vol. 11, pp. 1-33). Chichester, England: Wiley.

8. Ajzen, I., Nichols, A. J., \& Driver, B. L. (1995). Identifying salient beliefs about leisure activities: Frequency of elicitation versus response latency. Journal of Applied Social Psychology, 25(16), 1391-1410.

9. Albarracín, D., Johnson, B. T., Fishbein, M., \& Muellerleile, P. A. (2001). Theories of reasoned action and planned behavior as models of condom use: A metaanalysis. Psychological Bulletin, 127(1), 142-161.

10. Armitage, C. J., \& Conner, M. (2001). Efficacy of the theory of planned behavior: A meta-analytic review. British Journal of Social Psychology, 40, 471 - 499.

11. Armitage, C. J., Conner, M., Loach, J., \& Willetts, D. (1999). Different perceptions of control: Applying an extended theory of planned behavior to legal and illegal drug use. Basic and Applied Social Psychology, 21(4), 301-316.

12. Arvey, R. D., \& Neel, C. W. (1974). Testing expectancy theory predictions using behaviorally based measures of motivational effort for engineers. Journal of Vocational Behavior, 4(3), 299-310. doi: 10.1016/0001-8791(74)90114-6

13. Bandura, A. (1977). Self-efficacy: Toward a unifying theory of behavioral change. Psychological Review, 84(2), 191-215.

14. Bandura, A. (1997). Self-efficacy: The exercise of control. New York: Freeman.

15. Bandura, A., \& Adams, N. E. (1977). Analysis of self-efficacy theory of behavioral change. Cognitive Therapy and Research, 1(4), 287-310.

16. Bandura, A., \& Locke, E. A. (2003). Negative selfefficacy and goal effects revisited. Journal of Applied Psychology, 88(1), 87-99.

17. Carlson, E. R. (1956). Attitude change through modification of attitude structure. Journal of Abnormal \& Social Psychology, 52, 256-261.

18. Cervone, D., \& Peake, P. K. (1986). Anchoring, efficacy, and action: The influence of judgmental heuristics on self-efficacy judgments and behavior. Journal of Personality and Social Psychology, 50(3), 492-501.
19. Collins, O., Dalton, M., \& Roy, D. (1946). Restriction of output and social cleavage in industry. Applied Anthropology, 5, 3, 1-14.

20. Dabholkar, P. A. (1999). Expectancy-value models. In P. E. Earl \& S. Kemp (Eds.), The elgar companion to consumer research and economic psychology (pp. 200-208). Cheltenham, UK: Edward Elgar.

21. De Fleur, M. L., \& Westie, F. R. (1958). Verbal attitudes and overt acts: An experiment on the salience of attitudes. American Sociological Review, 23, 667-673.

22. Eagly, A. H., \& Chaiken, S. (1993). The psychology of attitudes. Fort Worth, TX: Harcourt Brace.

23. Ekerdt, D. J. (1998). Workplace norms for the timing of retirement. In K. W. Schaie \& C. Schooler (Eds.), Impact of work on older adults. (pp. 101142). New York, NY US: Springer Publishing Co.

24. Feather, N. T. (1959). Subjective probability and decision under uncertainty. Psychological Review, 66, 150-164.

25. Feather, N. T. (Ed.). (1982). Expectations and actions: Expectancy-value models in psychology. Hillsdale, NJ: Erlbaum.

26. Fishbein, M. (1963). An investigation of the relationships between beliefs about an object and the attitude toward that object. Human Relations, 16, 233-240.

27. Fishbein, M. (1967). A consideration of beliefs and their role in attitude measurement. In M. Fishbein (Ed.), Readings in attitude theory and measurement (pp. 257-266). New York: Wiley.

28. Fishbein, M., \& Ajzen, I. (1975). Belief, attitude, intention, and behavior: An introduction to theory and research. Reading, MA: Addison-Wesley.

29. Fishbein, M., \& Ajzen, I. (2010). Predicting and changing behavior: The reasoned action approach. New York: Psychology Press.

30. Fraser, R. T., Johnson, K., Hebert, J., Ajzen, I., Copeland, J., Brown, P., \& Chan, F. (2010). Understanding employers' hiring intentions in relation to qualified workers with disabilities: Preliminary findings. Journal of Occupational Rehabilitation, 20(4), 420-426. doi: 10.1007/s10926-009-9220-1

31. Freeman, L. C., \& Ataoev, T. (1960). Invalidity of indirect and direct measures of attitude toward cheating. Journal of Personality, 28, 443-447. 
32. Gagné, C., \& Godin, G. (2000). The theory of planned behavior: Some measurement issues concerning belief-based variables. Journal of Applied Social Psychology, 30(10), 2173-2193.

33. Graen, G. (1969). Instrumentality theory of work motivation: Some experimental results and suggested modifications. Journal of Applied Psychology, 53(2, Pt.2), 1-25. doi: 10.1037/h0027100

34. Greenwald, A. G., Poehlman, T. A., Uhlmann, E., \& Banaji, M. R. (2009). Understanding and using the implicit association test: III. Meta-analysis of predictive validity. Journal of Personality and Social Psychology, 97(1), 17-41.

35. Himelstein, P., \& Moore, J. (1963). Racial attitudes and the action of Negro and white background figures as factors in petition-signing. Journal of Social Psychology, 61(2), 267-272.

36. Iaffaldano, M. T., \& Muchinsky, P. M. (1985). Job satisfaction and job performance: A meta-analysis. Psychological Bulletin, 97(2), 251-273.

37. Judge, T. A., Thoresen, C. J., Bono, J. E., \& Patton, G. K. (2001). The Job Satisfaction-Job Performance Relationship: A Qualitative and Quantitative Review. Psychological Bulletin, 127(3), 376-407.

38. Kaplan, K. J., \& Fishbein, M. (1969). The source of beliefs, their saliency, and prediction of attitude. Journal of Social Psychology, 78(1), 63-74.

39. Kinicki, A. J., McKee-Ryan, F. M., Schriesheim, C. A., \& Carson, K. P. (2002). Assessing the Construct Validity of the Job Descriptive Index: A Review and Meta-Analysis. Journal of Applied Psychology, 87(1), 14-32.

40. Landy, F. J. (1989). Psychology of work behavior. Pacific Grove, CA: Brooks/Cole.

41. LaPiere, R. T. (1934). Attitudes vs. actions. Social Forces, 13, 230-237.

42. Lawler, E. E., \& Suttle, J. L. (1973). Expectancy theory and job behavior. Organizational Behavior \& Human Performance, 9(3), 482-503. doi: 10.1016/0030-5073(73)90066-4

43. Linn, L. S. (1965). Verbal attitudes and overt behavior: A study of racial discrimination. Social Forces, 43, 353-364.

44. Litt, M. D. (1988). Self-efficacy and perceived control: Cognitive mediators of pain tolerance. Journal of Personality and Social Psychology, 54(1), 149-160.
45. Mitchell, T. R., \& Biglan, A. (1971). Instrumentality theories: Current uses in psychology. Psychological Bulletin, 76(6), 432-454. doi: 10.1037/ h0031831

46. Osgood, C. E., Suci, G. J., \& Tannenbaum, P. H. (1957). The measurement of meaning. Urbana, IL: University of Illinois Press.

47. Peak, H. (1955). Attitude and motivation. In M. R. Jones (Ed.), Nebraska symposium on motivation (Vol. 3, pp. 149-189). Lincoln, NE: University of Nebraska Press.

48. Pearson, C. M., Andersson, L. M., \& Porath, C. L. (2005). Workplace Incivility. In S. Fox \& P. E. Spector (Eds.), Counterproductive work behavior: Investigations of actors and targets. (pp. 177-200). Washington, DC US: American Psychological Association.

49. Petkova, K. G., Ajzen, I., \& Driver, B. L. (1995). Salience of anti-abortion beliefs and commitment to an attitudinal position: On the strength, structure, and predictive validity of anti-abortion attitudes. Journal of Applied Social Psychology, 25(6), 463-483.

50. Petty, R. E., \& Cacioppo, J. T. (1986). Communication and Persuasion: Central and peripheral routes to attitude change. New York: Springer Verlag.

51. Robbins, S. P., \& Judge, T. A. (2010). Organizational behavior (14 ed.). Upper Saddle River, NJ: Prentice Hall.

52. Rosenberg, M. J. (1956). Cognitive structure and attitudinal affect. Journal of Abnormal and Social Psychology, 53, 367-372.

53. Saari, L. M., \& Judge, T. A. (2004). Employee attitudes and job satisfaction. Human Resource Management, 43(4), 395-407. doi: 10.1002/hrm.20032

54. Smith, P. C. (1974). The development of a method of measuring job satisfaction: The Cornell studies. In E. A. Fleishman \& A. R. Bass (Eds.), Studies in personnel and industrial psychology (3rd ed.). Homewood, IL: Dorsey.

55. Smith, P. C., Kendall, L. M., \& Hulin, C. L. (1969). The measurement of satisfaction in work and retirement: A strategy for the study of attitudes.: Rand Mcnally.

56. Tversky, A., \& Kahneman, D. (1974). Judgment under uncertainty: Heuristics and biases. Science, 185(4157), 1124-1131. 
57. van den Putte, B. (1993). On the theory of reasoned action. Dissertation, University of Amsterdam, The Netherlands.

58. van der Pligt, J., \& Eiser, J. R. (1984). Dimensional salience, judgment and attitudes. In J. R. Eiser (Ed.), Attitudinal judgment (pp. 43-63). New York: Springer-Verlag.

59. Van Eerde, W., \& Thierry, H. (1996). Vroom's expectancy models and work-related criteria: A meta-analysis. Journal of Applied Psychology, 81(5), 575-586. doi: 10.1037/0021-9010.81.5.575

60. Viswesvaran, C., \& Ones, D. S. (2000). Perspectives on models of job performance. International Journal of Selection \& Assessment, 8(4), 216-226.

61. Vroom, V. H. (1964). Work and motivation. New York: Wiley.

62. Weinberg, R. S., Gould, D., Yukelson, D., \& Jackson, A. (1981). The effect of preexisting and manipulated self-efficacy on a competitive muscular endurance task. Journal of Sport Psychology, 3(4), 345-354.

63. Wicker, A. W. (1969). Attitudes versus actions: The relationship of verbal and overt behavioral responses to attitude objects. Journal of Social Issues, 25(4), 41-78. 